\title{
The Influences Of Macroeconomic Forces On The Value-Momentum Spread Of Global Equities
}

Heng-Hsing Hsieh, PhD, CFA, University of the Western Cape, South Africa Kathleen Hodnett, PhD, University of the Western Cape, South Africa Paul van Rensburg, PhD, University of Cape Town, South Africa

\begin{abstract}
We extend our prior research on the determinants of the value-momentum spread of global equities to investigate the macroeconomic influences on this spread. The common arbitrage pricing theory (APT) macroeconomic forces identified by Chen, Roll and Ross (1986) are employed in a univariate test. Two significant variables extracted from the univariate test include the growth in the industrial production of advanced economies and the U.S. dollar strength relative to the currencies of developed economies. When these two variables are included in a two-factor regression, it is found that the industrial production growth is negatively correlated with the value-momentum spread, while the U.S. dollar strength is positively correlated with the value-momentum spread. Due to the fact that the value-momentum spread declines near the market peak and increases when the market crashes, the growth in industrial production could be regarded as an expansionary indicator and the U.S. dollar strength could be regarded as a contractionary indicator for future economic trends.
\end{abstract}

Keywords: Style Timing; Style Rotation; Economic Cycle; Global Financial Crisis; Economic Indicators; Active and Passive Portfolio Management

\section{INTRODUCTION}

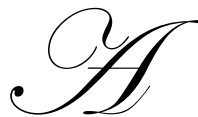

ctive fund managers have an objective of outperforming the broad market index via their unique style allocation or stock picking strategies. The results of our prior studies documented in Hsieh and Hodnett (2011) and Hsieh, Hodnett and van Rensburg (2012a) indicate that the performance of global equity funds are primarily driven by their active mix between value and momentum investment styles with negligible contribution from the stock picking activities of the fund managers. The style allocation decision is hence the driving force for a successful global equity fund strategy. Our prior study results documented in Hsieh and Hodnett (2012b) also show that the relative performance of global value stocks and momentum stocks, indicated by the value-momentum spread, is generally insignificant during the normal course of the economic cycle. However, when market conditions drastically worsen due to economic shocks, investor conservatism favours value stocks over momentum stocks. On the other hand, momentum stocks seem to perform relatively better than value stocks when investors are over-optimistic prior to market peaks. These findings suggest that the performance of the valuemomentum spread is closely related to the trends of the economic cycle.

Motivated by our prior findings, this paper intends to examine the influences of macroeconomic forces on the value-momentum spread of global equities. We attempt to explain the value-momentum spread of global equities over the period from 1 January 1991 to 31 December 2008 using pervasive macroeconomic forces of the arbitrage pricing theory (APT) identified by Chen, Roll and Ross (1986). Univariate regressions are first conducted on each of the APT factors to identify potentially significant variables. The collective power of the significant factors extracted from the univariate test is then tested in a multivariate framework over the examination period. Test results of this research provide insight into the timing of the important turning points in the economic cycle, which facilitates the style allocation decision for global equity funds. 


\section{LITERATURE REVIEW}

Empirical studies on the performance of actively-managed funds do not support the stock picking of fund managers as a value-added strategy. Based on the Barron's report documented by Bary (1997) cited in Sorensen, Miller and Samak (1998), only $11 \%$ of the U.S. mutual funds beat the performance of the S\&P 500 Index over the period from 1977 to 1997. The most recent report published by Standard \& Poor (S\&P) Indexes Versus Active (SPIVA) scorecard service indicates that the S\&P Composite 1500 Index outperforms 59.5\% of all U.S. domestic equity funds over the period from 2004 to 2009. During the same period, the S\&P Small Cap 600 Growth Index outperforms $76.88 \%$ of the U.S. domestic small cap growth funds, while the S\&P 500 Growth Index outperforms $71.22 \%$ of the U.S. domestic large cap growth funds. Only 2 out of 16 fund categories in the report beat their respective S\&P benchmarks: $51.39 \%$ of the real estate funds outperform the S\&P U.S. REIT Index and 52.36\% of the U.S. domestic large cap value funds outperform the S\&P 500 Value Index.

When the tests are extended to global equity funds, Hsieh and Hodnett (2011) construct global value and momentum indexes to replicate the underlying investment style mixes of 12 internationally-domiciled global equity funds based on the return decomposition approach of Sharpe (1992) over the period from 2002 to 2008. Test results indicate that most of the funds under analysis do not outperform the replicated style benchmarks. Similar results are obtained by Hsieh, Hodnett and van Rensburg (2012a) when the same tests are conducted on the South Africandomiciled global equity funds.

The limited contribution of the managers' stock picking ability, coupled with the evidence of underperformance of the mutual fund industry, suggest that fund managers should focus on tilting their investments towards the potentially outperforming investment styles as a value-added approach instead of picking their favourite stocks. In a further test, Hsieh and Hodnett (2012b) find that value stocks tend to underperform momentum stocks in global equity markets approximately 6 months prior to the peak of the business cycle when investors are overoptimistic. The excess gains earned by momentum stocks are lost in the subsequent stock market crash. The analysis of the periodic value-less-momentum return (that is, the value-momentum spread) reveals that the relative performance of global value stocks and momentum stocks are closely related to investor sentiments throughout the economic cycle. Therefore, the value-momentum style timing of global equities might be predictable, to a certain extent, by observing the co-movements of some pervasive macroeconomic forces.

Kao and Shumaker (1999) conduct tests in order to determine the predictability of the timing of switching between the value and growth investment styles. They support the view that style timing is likely to be driven by economic fundamentals and state that "...business cycles and trends in earnings underpin the differences in returns between the value and growth segments of the stock market and that these fundamental relationships persist; therefore, abnormal return opportunities exist for short-term switching strategies" (Kao and Shumaker, 1999: 39). Kao and Shumaker (1999) identify seven macroeconomic variables as potential determinants of value-growth timing. These variables include the yield-curve spread, the real bond yield, the corporate credit spread, the highyield spread, the forecasted GDP growth, the earnings-yield gap and the historical CPI. These factors represent key indicators of the stage of the business cycle. The results of their study reveal that the yield-curve spread, the real bond yield and the forecasted GDP growth are positively correlated with the 12-month forward value premium. The earnings-yield gap is the only variable that is negatively correlated with the 12-month forward value premium.

Amenc, Philippe, Lionel and Sfeir (2003) conduct further research on the predictability of style timing on the S\&P style indexes over the period from 2000 to 2002 . Their objective is to develop systematic timing strategies for market neutral funds that aim at delivering absolute returns over the full business cycle. They adopt a robust dynamic multifactor modelling approach that systematically forecasts the optimal style allocations of the market neutral strategy. The explanatory variables considered by the model include the term structure of interest rates, the slope of the term structure, the quantity of risk proxied by the historical volatility and the implied volatility, the price of risk proxied by the credit spread and the value proxies such as book-to-market ratio, earnings yield and dividend yield. The variables are updated over time. The optimization procedure for the market neutral strategy is conducted on the S\&P 500 Index (large cap), the S\&P Large Cap Growth Index, the S\&P Large Cap Value Index and the Russell 2000 Index (small cap). The results of the portfolio optimization indicate that the S\&P Value Index receives positive weights in almost all of the months over the 3-year out-of-sample period. On the other hand, the S\&P 
Growth Index is held short in most of the months under review. The weights allocated to the S\&P 500 Index (large cap) and the Russell 2000 Index (small cap) are mixed. This evidence supports the view of Kao and Shumaker (1999) that the most dominant and predictable style timing strategy is to switch between the value and the growth investment styles. The style timing strategy achieves a $10.9 \%$ annualized return with an annualized standard deviation as low as $4.71 \%$. During the same period, the S\&P 500 Index has an annualized return of $-18.03 \%$ and an annualized standard deviation of $18.72 \%$. The strategy also provides good downside protection in that it has downside standard deviation of $2.26 \%$ compared to $11.49 \%$ of the S\&P 500 Index, and the maximum monthly drawdown of $-1.56 \%$ compared to $-11 \%$ of the S\&P 500 Index.

Mutooni and Muller (2007) examine the profitability of style timing strategies on the JSE Securities Exchange in South Africa using macroeconomic variables over the period from 1994 to 2006. The variables employed by their research include the yield curve spread, the corporate credit spread, the earnings-yield gap, the equity risk premium, the inflation rate, the index of coincident economic indicators, the rate of change of M3 money supply, the All Share Index (ALSI) returns and the index of leading economic indicators. A time-series forecasting model is used to determine the timing to switch between the value and the growth indexes. The strategy invests fully in the value index at the beginning of 1994 but switches to the growth index if the model indicates that the valuegrowth spread will narrow over the next two consecutive months. The results indicate that the timing strategy successfully outperforms the ALSI, the value index and the growth index over the examination period. The cumulative return over the 13 -year period is as high as $745 \%$, compared to $675 \%, 307 \%$ and $432 \%$ being achieved by the value index, the growth index and the ALSI respectively.

\section{METHODOLOGY}

The value-momentum spread of global equities computed in Hsieh and Hodnett (2012b) is adapted for this research. The five pre-specified macroeconomic variables employed to explain the value-momentum spread include the monthly growth rate for the industrial production of advanced economies, the U.S. dollar return relative to the currency composite of advanced economies, the market risk premium, the U.S. term structure of interest rates and the year-on-year percentage change in the consumer price index (CPI) of advanced economies. These variables represent the APT factors of Chen et al (1986) that drive global equity returns. Amongst these variables, the term structure of interest rates is found to explain the forward value-growth spread significantly in the studies conducted by Kao and Shumaker (1999) and Mutooni and Muller (2007).

The monthly time-series data of the pre-specified macroeconomic variables are downloaded from the official website of the International Monetary Fund (IMF) over the period from 1 October 1990 to 31 December 2008. The market risk premium is proxied by the return difference between the MSCI World Index and the U.S. 3month Treasury bill. The U.S. term structure is computed as the 10-year U.S. Treasury bond yield in excess of the U.S. 3-month Treasury bill yield. The choice of the U.S-based term structure is due to the fact that U.S. dollar is used as the base currency for calculating equity returns. On the other hand, the growth rate of industrial production and the percentage change in CPI are based on advanced economies in order to provide more realistic indications regarding the current global economic conditions without being subject to abnormal economic shocks inherent in less developed economies. Similarly, the U.S. dollar currency return is computed relative to the currency composite of advanced economies. The advanced economies defined by the IMF include Australia, Austria, Belgium, Canada, Cyprus, Czech Republic, Denmark, Finland, France, Germany, Greece, Hong Kong, Iceland, Ireland, Italy, Japan, Luxembourg, Malta, Netherlands, New Zealand, Norway, Portugal, San Marino, Singapore, Slovakia, Slovenia, South Korea, Spain, Sweden, Switzerland, Taiwan, the United Kingdom and the United States of America.

The influences of the pre-specified macroeconomic variables on the value-momentum spread is determined by regressing the value-momentum spread of global equities on the lagged values of the respective variables in a univariate test as shown in Equation 1 over the examination period from 1 January 1991 to 31 December 2008:

$r_{\text {Value-Mom }, t}=\alpha_{\text {Value-Mom }}+b_{\text {Value-Mom }, k} \times F_{k, t-3}+\varepsilon_{\text {Value-Mom }, t}$ 
Where:
$\alpha_{\text {Value-Mom }}$
$F_{k, t-3}$
is the regression constant;
$b_{\text {Value-Mom, } k}$
is the value of the $k$ th macroeconomic variable in month $t-3$;
is the sensitivity of the value-momentum spread to the movements in the lagged 3-month $k$ th macroeconomic variable; and
$\varepsilon_{\text {Value-Mom }, t}$ is the random error term of the regression in month $t$.

The variables with significant slope coefficients from the univariate test are subsequently employed as the explanatory variables in a multivariate model as shown in Equation 2 over the examination period to determine the joint influences of the variables on the value-momentum spread of global equities:

$$
r_{\text {Value-Mom, },}=\alpha_{\text {Value-Mom }}+\sum_{j=1}^{J} b_{\text {Value-Mom }, j} \times F_{j, t-3}+\varepsilon_{\text {Value-Mom }, t}
$$

Where:
$F_{j, t-3}$
$J$
$b_{\text {Value-Mom, } j}$
is the value of the $j$ th macroeconomic variable in month $t-3$;
is the number of significant macroeconomic variables identified in the univariate test; and
is the sensitivity of the value-momentum spread to the movements in the lagged 3-month $j$ th macroeconomic variable.

\section{EMPIRICAL FINDINGS}

Since the global value-momentum spread declines significantly towards the market peak and recovers rapidly at the beginning of the market downturn, factors that correlate positively with the value-momentum spread are regarded as contractionary indicators of global economic activity. On the other hand, factors that correlate negatively with the value-momentum spread are regarded as expansionary indicators of global economic activity. The $R$-Squared produced by Equation 1 demonstrates the correlation between the value-momentum spread and the respective macroeconomic variables. The slope of the regression and its $t$-statistic provide indications of the direction and the degree of influence a specific variable has on the value-momentum spread. The regression statistics for the five pre-specified macroeconomic variables with their scatter plots are shown in Figure 1 through Figure 5.

The examination of the regression statistics suggests that the lagged 3-month monthly growth rate for the industrial production of advanced economies (refer to Figure 1) and the lagged 3-month U.S. dollar return relative to the currency composite of advanced economies (refer to Figure 2) are the only two variables that significantly explain the forward value-momentum spread over the examination period. While the monthly growth rate for the industrial production of advanced economies are negatively correlated with the forward value-momentum spread, the U.S. dollar return relative to the currency composite of advanced economies are positively correlated with the value-momentum spread. It is also noted that the negative influence of industrial production on the valuemomentum spread is mainly observed when industrial production is negative (refer to Figure 1). When industrial production is positive, its influence on the value-momentum spread is inconclusive.

Table 1 displays the regression statistics when the two significant variables are regressed on the global value-momentum spread over the examination period. The $p$-value of the regression indicates that the explanatory power of the two-factor regression is significant at the 5\% level. The slope coefficient for the lagged 3-month industrial production growth rate is negatively significant at a $1 \%$ level while the lagged 3-month U.S. dollar return is positively significant at a $10 \%$ level. The observed influences of these two variables on the value-momentum spread are supported by economic rationale. During economic turmoil, sliding industrial production and investor conservatism lead the value-momentum spread to increase. The value of the U.S. dollar relative to other currencies is likely to gain as funds in the global financial markets are flowing back to the U.S. Overall, the adjusted $R$-squared of the two-factor regression is only $4.25 \%$. This result is expected due to the fact that the value-momentum spread is only significant when the long-term economic trend is disturbed. That is, at the turning point of the economic cycle. 


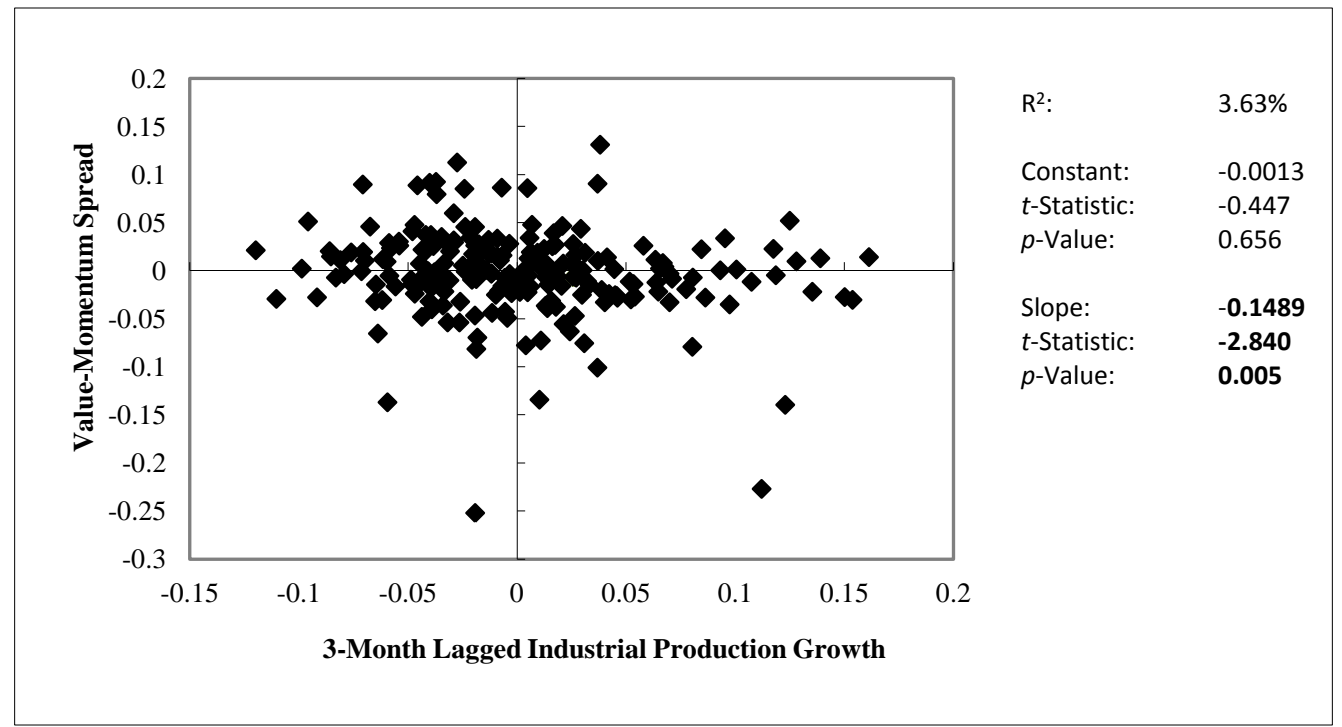

Figure 1: Monthly Growth for the Industrial Production of Advanced Economies

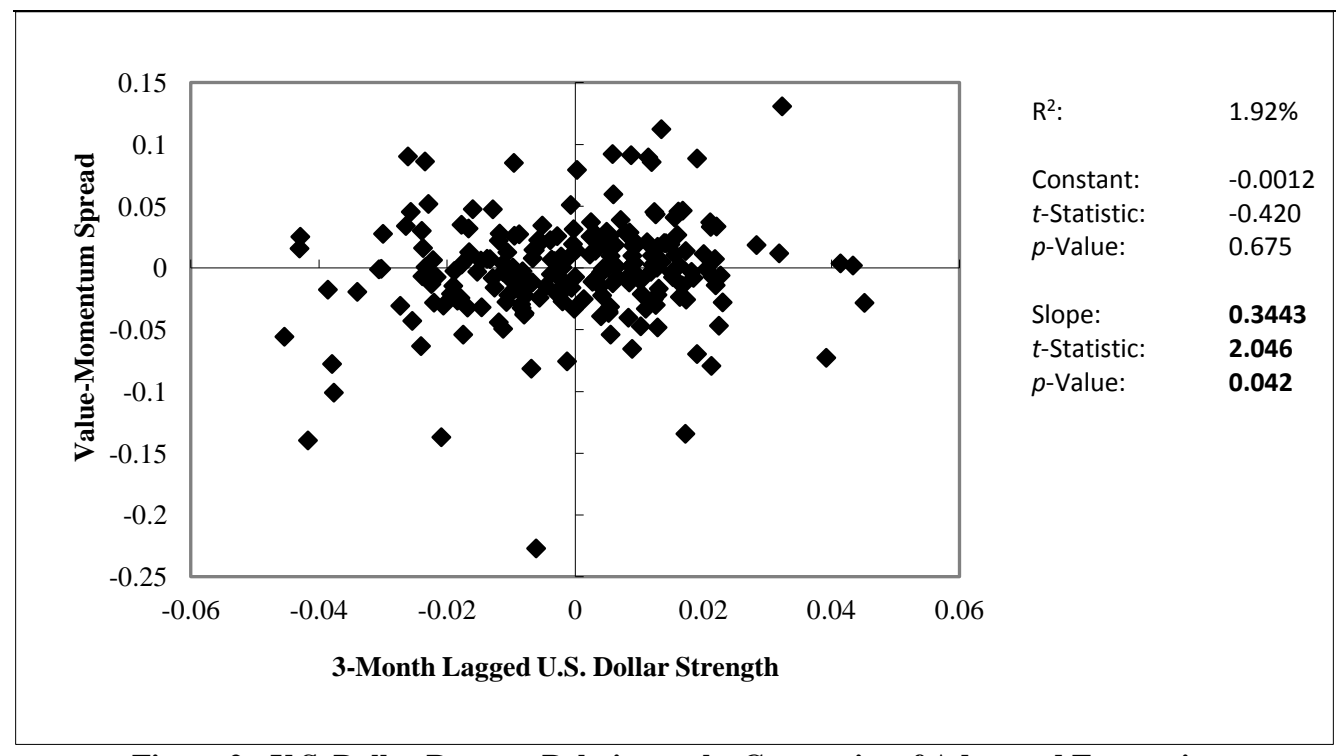

Figure 2: U.S. Dollar Returns Relative to the Currencies of Advanced Economies 


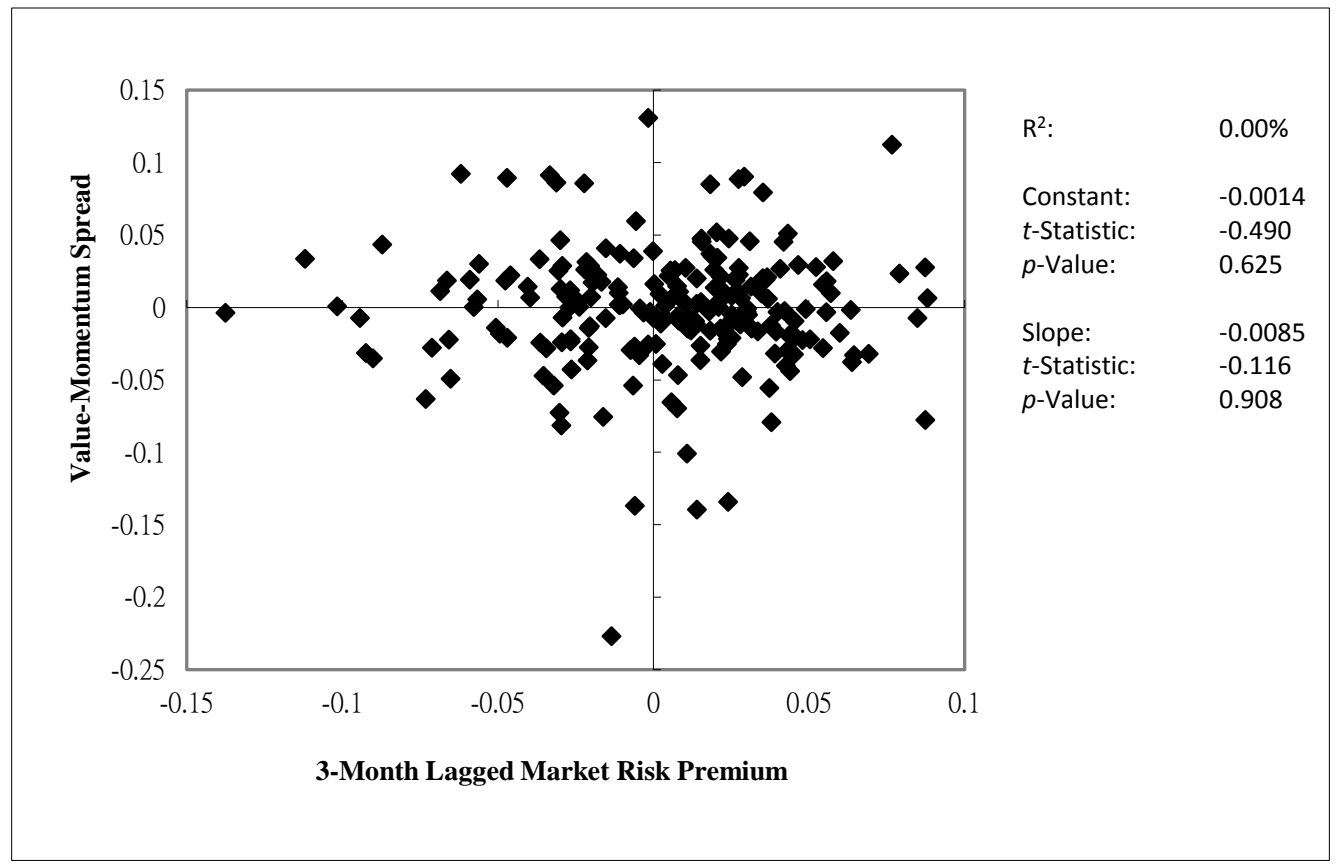

Figure 3: Market Risk Premium (MSCI World Return - USTB3M)

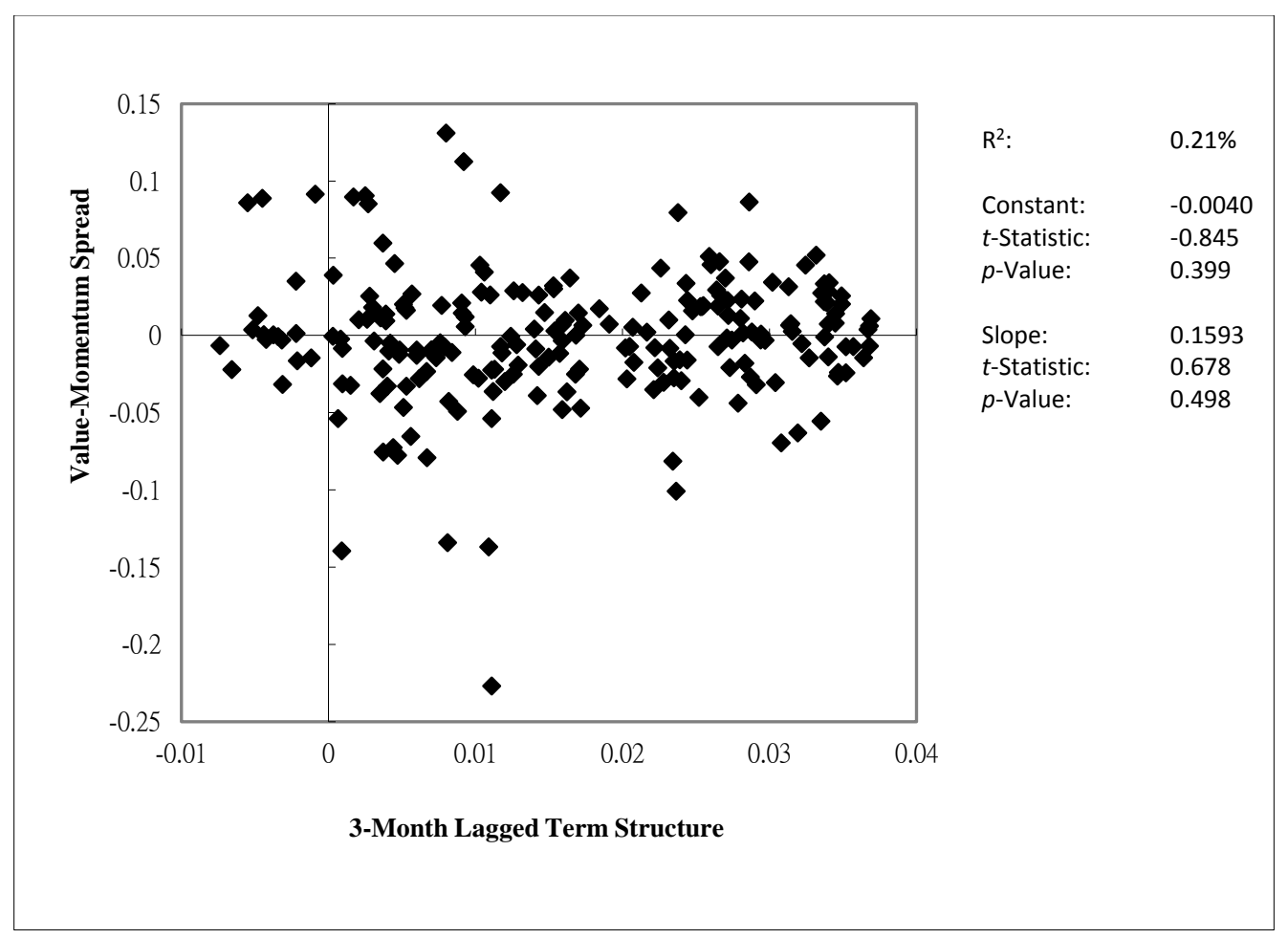

Figure 4: Term Structure (10-year U.S. Treasury Bond Yield - USTB3M) 


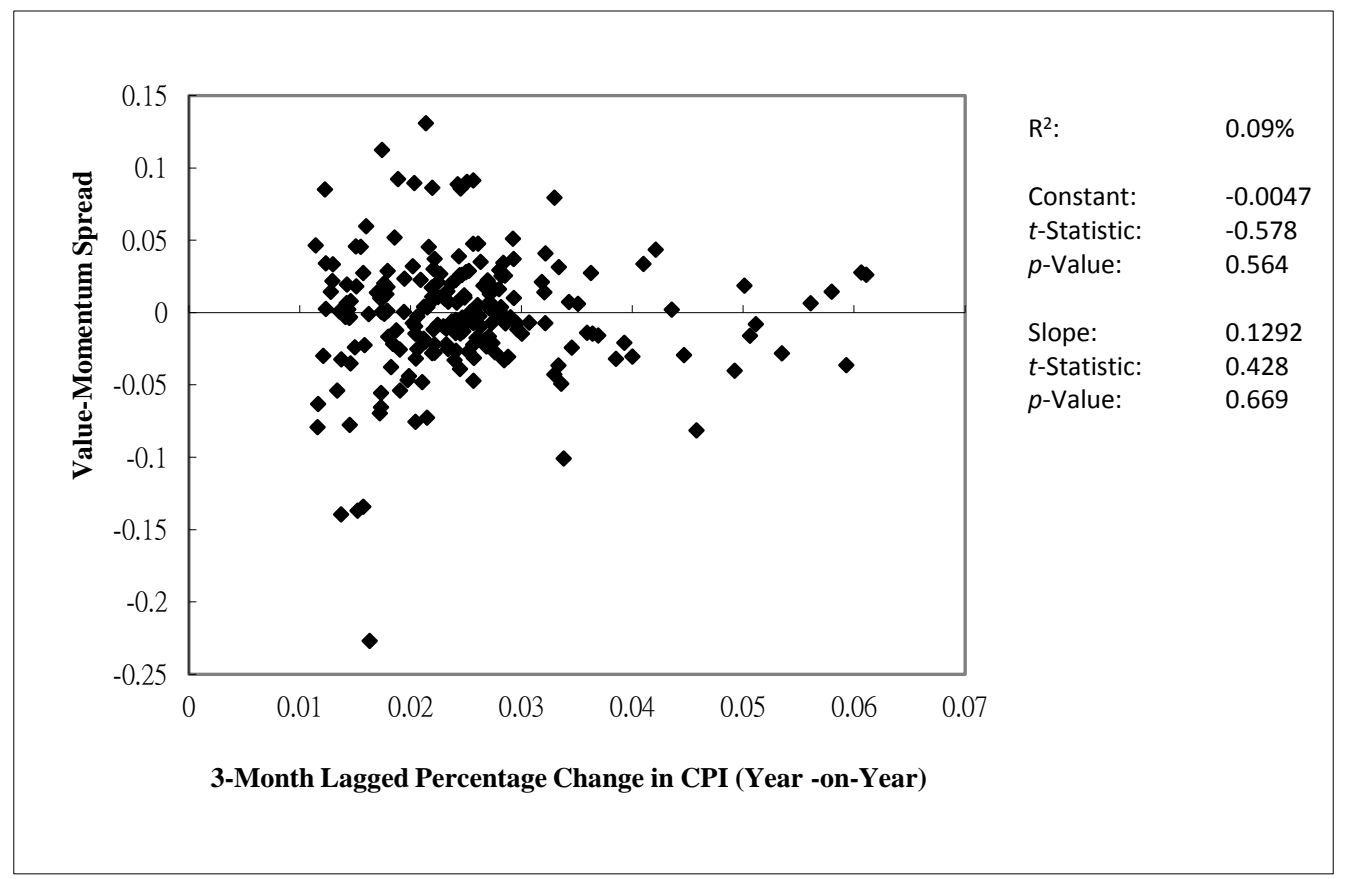

Figure 5: Percentage Change in CPI of Advanced Economies (Year-on-Year)

Table 1: Regression Statistics for the 2-Factor Global Value-Momentum Spread Forecasting Model

\begin{tabular}{|c|c|c|c|c|c|c|}
\hline $\mathrm{R}^{2}$ & : & $5.15 \%$ & & & \multirow[b]{5}{*}{$F$-Statistic } & \multirow[b]{5}{*}{ p-Value } \\
\hline Adjusted $\mathrm{R}^{2}$ & : & $4.25 \%$ & & & & \\
\hline Standard Error & : & $4.09 \%$ & & & & \\
\hline Observations & : & \multicolumn{3}{|c|}{216 (01 January 1991 to 31 December 2008) } & & \\
\hline ANOVA & & Df & SS & MS & & \\
\hline Regression & : & 2 & 0.0193 & 0.0097 & 5.7774 & 0.0036 \\
\hline Residual & : & 213 & 0.3560 & 0.0017 & & \\
\hline \multirow[t]{2}{*}{ Total } & : & 215 & 0.3753 & & & \\
\hline & & Coefficient & Std Error & $t$-Static & p-Value & \\
\hline Constant & : & -0.0010 & 0.0028 & -0.3724 & 0.7100 & \\
\hline $\mathrm{GIP}_{\mathrm{t}-3}$ & : & -0.1408 & 0.0523 & -2.6918 & 0.0077 & \\
\hline RUSD $_{\mathrm{t}-3}$ & : & 0.3070 & 0.1665 & 1.8440 & 0.0666 & \\
\hline
\end{tabular}

\section{CONCLUSION}

Our prior studies suggest that fund managers' stock picking activities do not provide economic benefits and the performance of global equity funds are primarily driven by the mix of the momentum and value investment styles. In addition, investor sentiments generally lead the value-momentum spread to increase during market turmoil, and decline during the subsequent economic recovery.

Using the five APT factors of Chen et al (1986) as candidate macroeconomic forces that drive the valuemomentum spread of global equities, it is found that the value-momentum spread is influenced negatively by the industrial production growth of the advanced economies and influenced positively by the strength of the U.S. dollar. Thus, the industrial production growth rate can be regarded as an expansionary indicator and the U.S. dollar strength can be regarded as a contractionary indicator for economic trend forecasting. Nevertheless, the negative relationship 
between industrial production and the value-momentum spread is mainly observed when industrial production is declining.

Since the value-momentum spread of global equities is only significant when the long-term economic trend is disturbed, the movements of the two significant macroeconomic variables could be used to detect major turning points of the economic cycle or economic shocks in making style allocation decisions. During economic downturn, a rising industrial production accompanied by declining U.S. dollar value could serve as a signal for fund managers to shift the funds from value stocks to momentum stocks. On the other hand, a declining industrial production with rising U.S. dollar value would suggest that the market peak is near and managers should start shifting funds into more defensive, value stocks. Suggested areas that demand further research include the development and application of tactical style allocation (TSA) strategies based on the forecasts of macroeconomic forces.

\section{ACKNOWLEDGEMENT}

This work is supported by the National Research Foundation (NRF) of South Africa. We wish to thank the research office of the University of the Western Cape for their support.

\section{AUTHOR INFORMATION}

Dr. Heng-Hsing Hsieh, CFA is the Head of Finance in the School of Business and Finance at the University of the Western Cape, South Africa. He is a CFA charterholder and a member of the South African Institute of Financial Markets (SAIFM). E-mail: ahsieh@uwc.ac.za. Corresponding Author.

Dr. Kathleen Hodnett is currently a Research Fellow (funded by the National Research Foundation (NRF) of South Africa) in the School of Business and Finance at the University of the Western Cape, South Africa. She is a member of the International Institute of Forecasters (IIF) and an associate member of the South African Institute of Financial Markets (SAIFM).

Prof. Paul van Rensburg is the Frank Robb Professor of Finance at the University of Cape Town, South Africa. He is the principal of Salient Quantitative Investment Management. E-mail: paul.vanrensburg@uct.ac.za.

\section{REFERENCES}

1. Amenc N, Goltz F and Le Sourd V (2006), “Assessing the Quality of Stock Market Indices”, EDHEC Risk and Asset Management Research Centre.

2. Amenc N, Philippe M, Lionel M and Sfeir D (2003), "Tactical Style Allocation - A New Form of Market Neutral Strategy", EDHEC Risk and Asset Management Research Centre.

3. Bary A (1997), "Changing Places", Barron's research report cited in Sorensen E H, Miller K L and Samak V (September/October 1998), "Allocating between Active and Passive Management", Financial Analysts Journal, vol 54, no 5, 18-31.

4. Chen N, Roll R and Ross S A (1986), "Economic Forces and Stock Market", Journal of Business, vol 59, no 3, 389-403.

5. Hsieh H and Hodnett K (2011), "Do Managers of Global Equity Funds Outperform Their Respective Style Benchmarks? An Empirical Investigation”, International Business and Economics Research Journal, vol 10, no 2, 1-10.

6. Hsieh H, Hodnett K and van Rensburg P (2012a), "Do Managers of Global Equity Funds Outperform Their Respective Style Benchmarks? Evidence from South Africa", International Business and Economics Research Journal, vol 11, no 3, 269-282.

7. Hsieh H and Hodnett K (2012b), "Dissecting the Value-Momentum Spread: Sector Allocation Effect Versus Country Allocation Effect", Journal of Applied Business Research, vol 28, no 2, 227-236.

8. Kao D and Shumaker R D (1999), "Equity Style Timing", Financial Analysts Journal, vol 55, no 1, 37-47.

9. Mutooni R and Muller C (2007), "Equity Style Timing", Investment Analysts Journal, no 65, 15-24.

10. Nofsinger J R (2005), The Psychology of Investing, 3rd Edition, Prentice Hall.

11. Page M J and Way C V (Summer 1992/1993), "Stock Market Overreaction: The South African Evidence", 
Investment Analysts Journal, no 36, 35-49.

12. Reilly F K and Brown K C (2003), Investment Analysis and Portfolio Management, 7th Edition, Thomson Learning.

13. Roll R (1977), “A Critique of the Asset Pricing Theory's Tests Part I: On Past and Potential Testability of the Theory", Journal of Financial Economics, vol 14, no 2, 129-176.

14. Roll R (September 1978), "Ambiguity When Performance is Measured by the Security Market Line", Journal of Finance, vol 33, no 4, 1051-1069.

15. Sharpe W F (1966), "Mutual Fund Performance", Journal of Business, vol 39, no 1, 119-138.

16. Sharpe W F (1992), "Asset Allocation: Management Style and Performance Measurement", Journal of Portfolio Management, vol 18, 7-19.

17. Sorensen E H, Miller K L and Samak V (1998), "Allocating between Active and Passive Management", Financial Analysts Journal, vol 54, no 5, 18-31.

18. Statman M (1999), "Behaviorial Finance: Past Battles and Future Engagements", Financial Analysts Journal, vol 55, no 6, 18-27.

19. Thaler R (1985), "Mental Accounting and Consumer Choice”, Marketing Science, no 4, 199-214. 
NOTES 